\title{
Public Spaces of Developing Countries Post COVID-19: A Reflection on Current Situation from Planning Perspective in Case of Kabul City, Afghanistan
}

\author{
Rashid A. Mushkani ${ }^{1,2}$, Haruka Ono ${ }^{3,4}$ \\ ${ }^{1}$ Graduate Student, Department of Architecture and Civil Engineering, Toyohashi University of Technology, Aichi, Japan \\ ${ }^{2}$ Assistant Instructor, Engineering Faculty, Kabul University, 1006 Kabul, Afghanistan; rashid.mushkan@ku.edu.af \\ ${ }^{3}$ Lecturer, Department of Architecture and Civil Engineering, Toyohashi University of Technology, Aichi, Japan \\ ${ }^{4}$ Center for Sustainable Development Studies, Toyo University; ono.haruka@ace.tut.ac.jp
}

\begin{abstract}
Social distancing, stay home \& stay safe and avoiding public space usage has been the slogan to battle against an invisible enemy (COVID-19 pandemic), these measures are placed by the government to minimize transmission of the disease between urban residents, In pace with developed countries many developing countries across the world as well simulated same measures to reduce transmission and contain the disease, although it is believed that the outcomes would be different (WHO, 2020), yet most of the residents are complying with public health officials recommendations, empty street, minimal public spaces, parks and plazas usage are evidence of this scenario. The aim of this paper is to examine the impacts of current situation i.e. COVID-19 pandemic countermeasure on public spaces, propose tentative planning and design incentives for developing countries and encourage research on how the planning and design of our cities can evolve and be more resilient for similar future challenges.
\end{abstract}

Keywords: Public space; planning; COVID-19; human behaviour; air pollution; Kabul city.

\section{INTRODUCTION}

Aftermath of current situation, many scenarios are possible for both types of countries; human interaction and their relationship with each other and built environment could be overwhelmingly altered, yet the depth of this alteration is unclear, currently primary means of communication between people is sign language in urban public spaces and digital communications on individual scale, both of them are emerging for expression of feelings with claims of getting to be the primary tools of interaction instead of physical, experiential and on in-situ observational communications in the developed countries, due to the lack of technological amenities for much of the developing countries the situation has not been the same. This article has measured some of the emerging changes and potentials in post COVID-19 world contextual to developing countries, mainly focused on Kabul city, Afghanistan.

As a consequence of temporary governmental policies to fight against the outbreak of the pandemic from a top down approach, life has been halted and due to the closure of businesses, educational and governmental institutions in Kabul city there has been a swing in behaviour of public space users on district and regional level; without reliable public transport residents used to commute by cars throughout the city, now automobiles are parked inside houses or parking's and users are outside commuting through sustainable gears, neighbourhood streets are without traffic, yet active and has become children's territory, see Fig.1. 
As of 2014 Afghanistan is in top five countries with highest death rate connected to outdoor air pollution (WHO) see Fig.2, even though in recent years the air quality is depredated and always gets worse in autumn and winter seasons, government is yet to act, poor quality fuel consumption, old and overused vehicles for transportation has been always identified as one of the major contributors to the air pollution not only in Kabul city, but in many developing cities across the world.

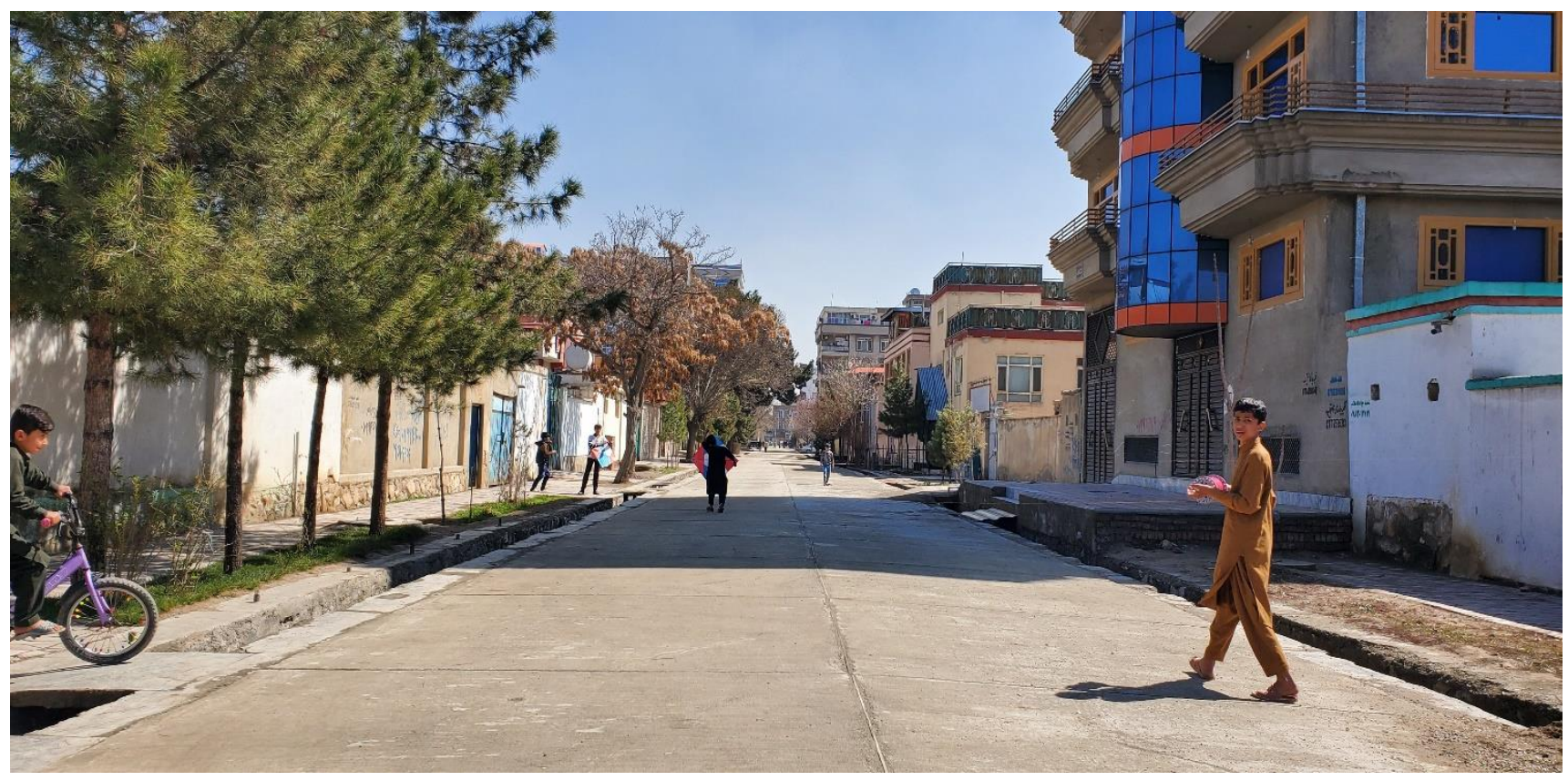

Fig. 1: District 15, Khair-Khana, Kabul. Children play outside in the street without fear of car accidents.

Annual mean concentrations of fine particulate matter (PM2.5) in urban areas $(\mu \mathrm{g} / \mathrm{m} 3), 2014^{*}$

Annual mean PM2.5 (ug/m3)
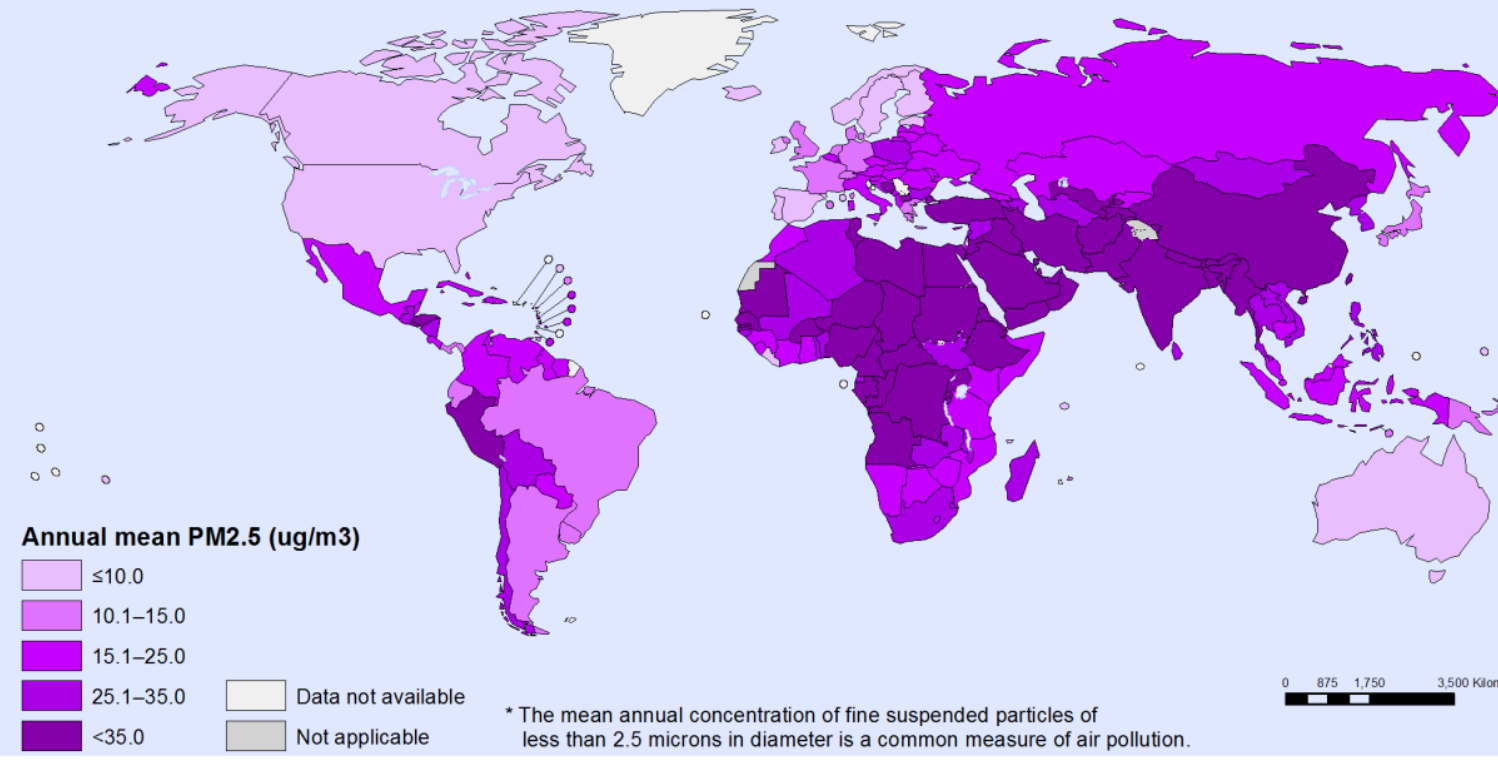

* The mean annual concentration of fine suspended particles of

less than 2.5 microns in diameter is a common measure of air pollution.

The boundaries and names shown and the designations used on this map do not imply the expression of any opinion whatsoever on the part of the World Health Organization concerning the legal status of any country, ternitory, city or area or of its authonties, or concerning the delimitation of its fronters or boundaries. Dotted and dashed lines on maps represent approximate border lines for which there may not yet be full agreement

Data Source: World Health Organization Map Production: Information Evidence and Research (IER)

World Health Organization

Fig. 2: Afghanistan is in top five countries with highest death rate connected to outdoor air pollution. 
International Journal of Interdisciplinary Research and Innovation

Vol. 8, Issue 3, pp: (1-5), Month: July - September 2020, Available at: www.researchpublish.com

\section{ANALYSIS AND DISCUSSION}

Majority of residents in Kabul city are economically categorized low - mid income, due to their reliance on daily income and fear of death caused by poverty, stricter measure of quarantine cannot be implemented. Urban built environment of the city is mixed of planned, unplanned and traditional neighbourhoods, prior to COVID-19 even automobiles were used in streets with no designated capacity for vehicular transportation, on a community scale the residents behaviour had transformed streets, walkways and specially sidewalks in to an unfriendly environment, streets are often occupied with cars and sidewalks are mixed-up and raised to accommodate parking area, leading to walkability obstructions, rigid environment and unsafe routes.

Currently quarantine measures offers a range of opportunities for both urban planners and urban residents, it is time to reflect on public space usage and sustainable commuting, and to the degree which commuting is required. We must learn and carry out the positive environmental and human health outcome of today's measures in to the future policies of the current and in to the planning for new cities. Adaptive reuse of the buildings, public space usage, our perception of leisure activities in restaurants, strict automobile commuting, all of these factors contribute significantly in improving air quality of the city. (Nieuwenhuijsen. 2020)

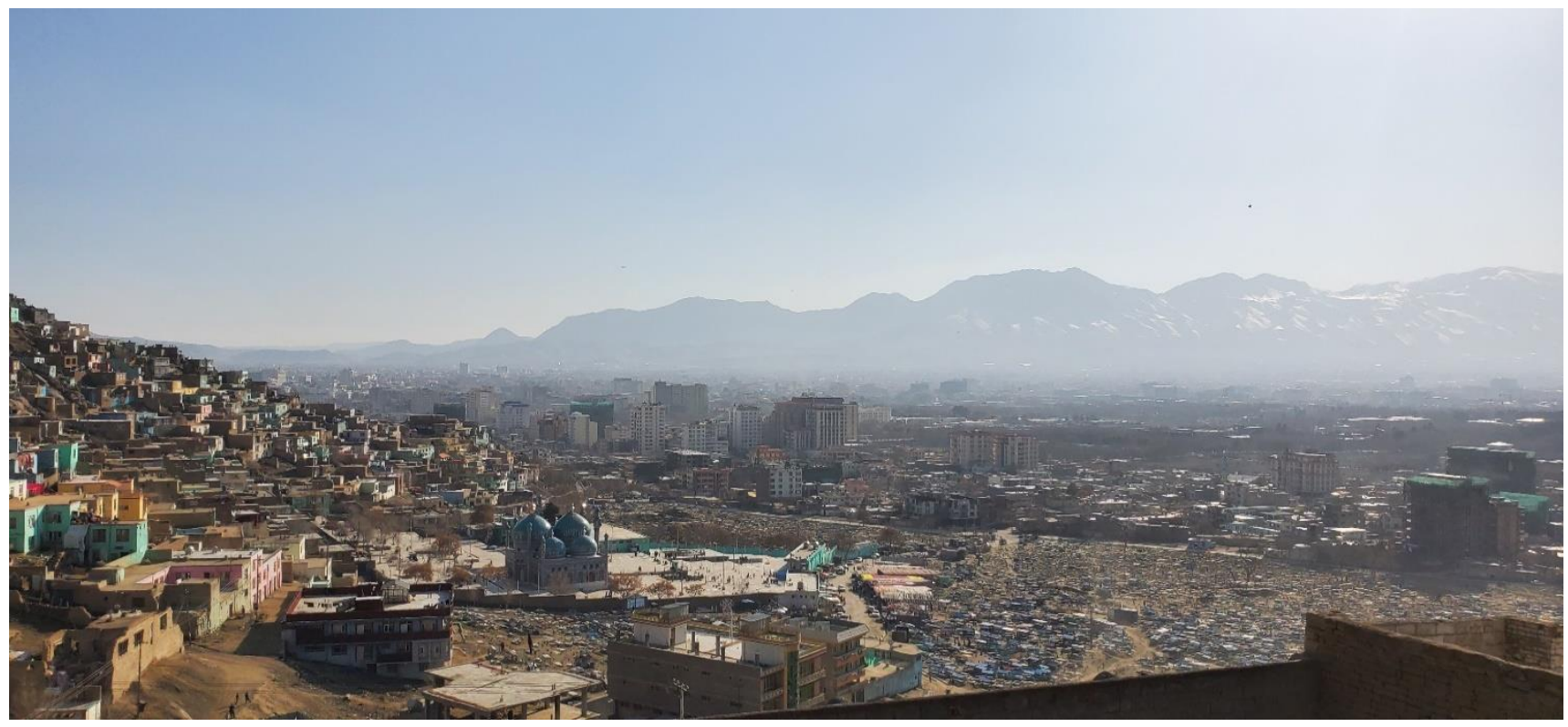

Fig. 3: Kabul city skyline. 18 March 2020. Prior quarantine initiation, visible air pollution.

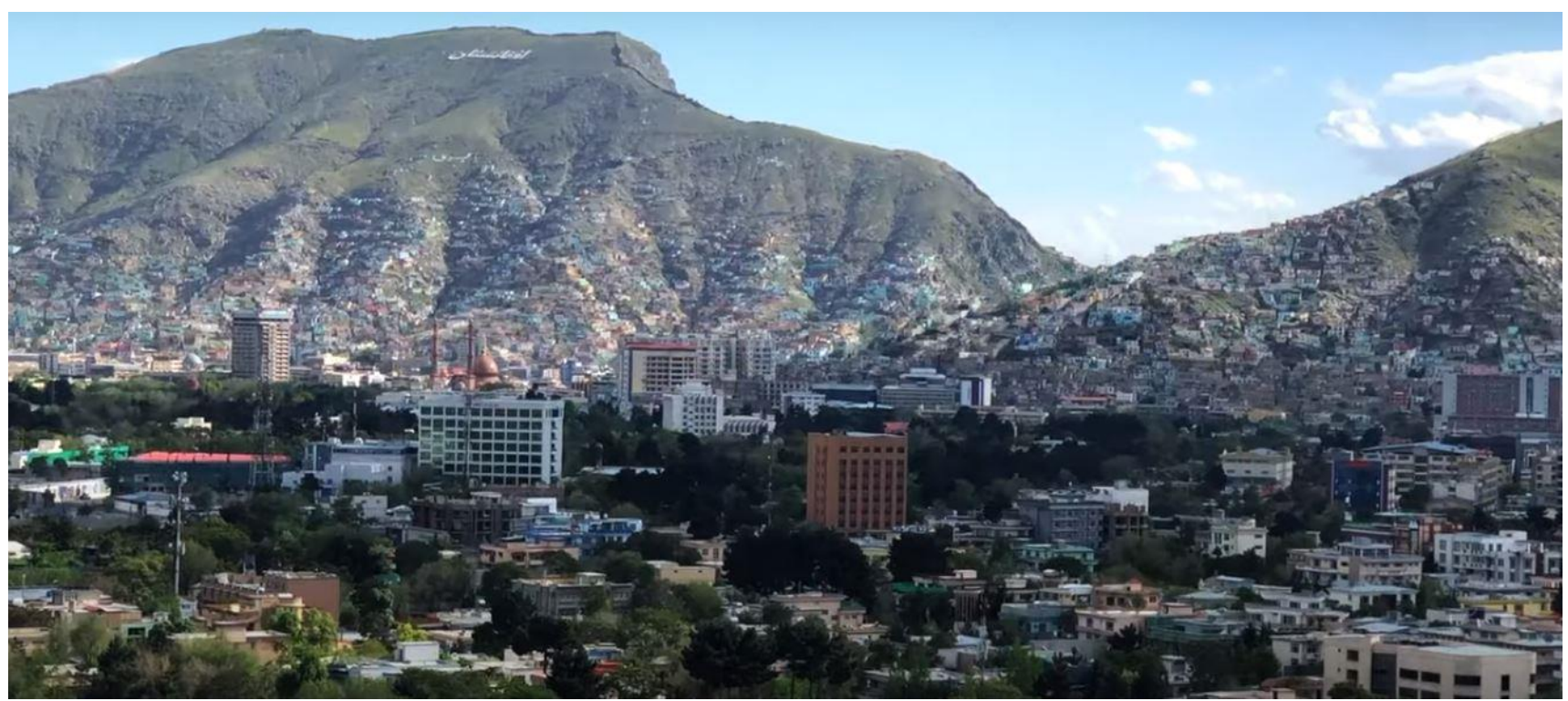

Fig. 4: Kabul city skyline. Taken from opposite side of the mountain to the prior picture. 30 April 2020. Visible clean air. 
The government's policy regarding adaptive reuse of some public buildings for accommodation of COVID-19 patients, neighbourhood supermarkets control and distribution of bread throughout bakeries in communities has reinforced the role of public amenities, this process has also lead youths and children to use public spaces within their neighbourhoods and engaging in interaction with their physical environment (Whyte. 1980), resulted minimal automobile usage which has paved the way for strengthening the sense of community and place, these mandates while being praised by some, should be maintained till crisis unfolds and adapted to normal daily lives post this pandemic. Nonetheless fundamental economic changes are inevitable with the global warming effects lurking behind the scenes, this is a great opportunity to alter city planning and urban development technics for cities within developing countries.

Although strict lockdown measure for developing countries is not advised by World Health Organization due to poverty, yet the indirect outcomes of current measures will be in line with the Sustainable Development Goals of United Nations. Proper governance can play a significant role in further putting into practice of these changes which will have health and environmental implication; some organizational restructuring at the national planning level, creation of public space incentives and policies, mixed use developments, and creating walking and cycling infrastructure will contribute to streets dynamism, users health and air quality.

Densification in urban areas along with compactness characteristics, city must support pedestrianized walkways large enough to house physical and social distancing measures as new norms of queuing are emerging at the entrances of public amenities. Public space appearance can be fundamentally altered by discouraging automobile traffic and promoting pedestrianized, cycling and other sustainable traffic flow as planned for Milan city, Italy "The city has announced that $35 \mathrm{~km}$ (22 miles) of streets will be transformed over the summer" (The Guardian 2020). The current situation is acting as a catalyst for cycling expansion, clean public transport which is accessible to everyone, these reflection need more relevance research and practices for creation of future safe and healthy environment.

\section{CONCLUSION}

Humans are connected and dependent with each other, yet again emphasized by this crisis, role of built environment and public spaces to nurture these connections which can lead to collective actions has never been strong as today. This is an opportunity to thoroughly examine our built environment, furthermore positive changes are evident as dependence on sustainable commuting compared to automobile, combination of different housing typologies in neighbourhoods and existence of supportive socioeconomic zones within district clusters not only improve the air quality, but also contributes to mitigation of urban heat island and air pollution plus creating a sense of place and social bond between urban residents, all these can lead to a more resilient future city.

Declaration of interest: None'

Competing interest: None'

This research did not receive any specific grant from funding agencies in the public, commercial, or not-for-profit sectors. Corresponding Author: Rashid A. Mushkani; rashid.mushkan@ku.edu.af

Address: Department of Architecture and Civil Engineering, Toyohashi University of Technology, 1-1 Hibarigaoka, Tempaku-cho, Toyohashi, Aichi, Japan. 441-8580

\section{REFERENCES}

[1] WHO, 2020. Global Surveillance for human infection with coronavirus disease (COVID-19), Interim Guidance.

[2] Nieuwenhuijsen, M.J., 2020. Urban and transport planning pathways to carbon neutral, livable and healthy cities; A review of the current evidence. Environment International https://doi.org/10.1016/j.envint.2020.105661 (Accessed: 30 April 2020).

[3] The Guardian (2020) Milan announces ambitious scheme to reduce car use after lockdown [Online]. Available at: https://www.theguardian.com/world/2020/apr/21/milan-seeks-to-prevent-post-crisis-return-of-traffic-pollution (Accessed: 10 May 2020).

[4] David Engwicht, 1999. Street Reclaiming: Creating Livable Streets and Vibrant Communities, Pluto Press.

[5] Edward T. Hall, 1973. The Silent Language, Anchor. 
[6] Jan Gehl, Birgitte Svarre, 2013. "How to Study Public Life", Island Press, Washington.

[7] Jan Gehl, 2011. "Life between Buildings: Using Public Space”, Island Press, Washington.

[8] Gehl, J., 2013. Cities for people. Island Press.

[9] Whyte, W., 1980. The Social Life of Small Urban Spaces. Project for Public Spaces, New York, NY.

[10] The BBC (2016) Polluted air affects 92\% of global population, says WHO [Online]. Available at: https://www.bbc.com/news/health-37483616 (Accessed: 11 May 2020). 